\title{
O MODELO DE GESTÃo TERRITORIALIZADA DA POLÍTICA DE EDUCAÇÃO ESCOLAR INDí- GENA NO ESTADO DA BAHIA
}

Carlos Rafael da Silva ${ }^{1}$

Neste texto, a partir das pesquisas desenvolvidas pelo Projeto Observatório da Educação Escolar Indigena - Núcleo do Território Etnoeducacional Yby Yara, abordaremos algumas questóes referentes aos limites institucionais do modelo de gestão dos Territórios Etnoeducacionais para a execução de uma politica de educação escolar indígena intercultural. O Projeto propõe um conjunto de ações voltado para o protagonismo indígena, por meio da formação de professores e pesquisadores indigenas, produção de conhecimento intercultural e articulação política e acadêmica, estimulando e subsidiando iniciativas educacionais e de pesquisa nos recém-criados Territórios Etnoeducacionais. Assim, pretendemos discutir algumas questões teórico-metodológicas referentes à implementação de políticas públicas para povos indígenas. A expectativa é que essa discussão contribua na avaliação dessas políticas, tema ainda pouco explorado, seja na ação governamental, seja na pesquisa cientifica.

Palavras-chave: políticas públicas; educação escolar indígena; Territórios Etnoeducacionais.

\section{INTRODUÇÃo}

Fazem parte da história recente da relação entre povos indígenas e o Estado brasileiro ações e ideologias concebidas com base na concepção de integração cultural à sociedade nacional. Os povos indígenas eram considerados, até recentemente, seres em transição numa linha imaginária, com implicações substantivas, que podemos traçar como tendo dois extremos: o indígena e o 'civilizado'. A partir da Constituição Cidadã de 1988, inaugura-se um novo paradigma jurídico e político, reconhecendo-se o direito dos índios de serem eles mesmos, manten-

1 Mestrando em Ciências Sociais na Universidade Federal da Bahia. Bolsista do Conselho Nacional de Desenvolvimento Científico e Tecnológico (CNPQ). Esse texto foi escrito em colaboração com Jéssica Torres Costa e Silva, indígena do povo Xucuru-Kariri e pesquisadora da política indigenista no estado da Bahia. 
do suas tradições, costumes, línguas e o direito originário sobre os territórios que ocupam. A Constituição abre prerrogativa para leis, regimentos, regulamentos, planos e ações governamentais que reconheçam o direito a uma educação formal para indígenas, pautada nos princípios de interculturalidade, especificidade e diferença. Subjacente a esse reconhecimento, está a ideia de uma sociedade não homogênea, algo que nunca fomos, mas sim multicultural.

Porém, em termos de políticas públicas, a legislação em vigor é apenas um primeiro passo para o reconhecimento da diferença. Para efetivar uma verdadeira política de educação intercultural nas aldeias indígenas, deve-se observar não somente o conteúdo das regras, mas também os processos que envolvem sua implementação. Diante disso, deixa-se de lado uma concepção de 'cumpra-se' da política pública, como se a mera regulamentação fosse elemento suficiente para a sua efetividade, pois a operacionalização apresenta inúmeros percalços ao nível local. Neste texto pretendemos apresentar os problemas de implementação da política de educação intercultural no estado da Bahia, a partir da análise do novo modelo de gestão definido como Território Etnoeducacional.

Essa avaliação está intrinsecamente relacionada ao protagonismo político de indivíduos e grupos indígenas. Ela é baseada nas pesquisas que realizamos em projetos acadêmicos e em nossa atuação em espaços do governo e dos movimentos indígenas no estado da Bahia. Em relação ao governo, ambos participamos da Comissão Gestora do Território Etnoeducacional, que será descrita ao longo do texto. No âmbito dos movimentos indígenas, participamos de organizações informais, como o Fórum Estadual de Educação Escolar Indígena da Bahia (Forumeiba), instância que há mais de uma década discute a política educacional.

Também atuamos como pesquisadores no Projeto Observatório da Educação Escolar Indígena ${ }^{2}$, que desde o ano de 2010 realiza um diagnóstico pioneiro da situação educacional dos povos indígenas no estado da Bahia, a partir de informações coletadas por professores/pesquisadores em suas aldeias, além de contar com linguistas, antropólogos, historiadores e cientistas políticos indígenas e não indígenas.

Os resultados do Projeto evidenciam déficits de implementação da atual política de educação formal para indígenas e os condicionantes institucionais sobre a efetividade do cumprimento da legislação que a regulamenta. Assim, pretendemos expor esses déficits, bem como correlacioná-los aos condicionantes institucionais, em especial, o atual regime de colaboração entre as três esferas de governo: municipal, estadual e federal. Com isso acreditamos contribuir para a concretização efetiva de uma política de educação intercultural para indígenas no estado.

$\mathrm{O}$ artigo divide-se em cinco tópicos. Primeiramente apresentamos um breve histórico da política aqui examinada, tendo como marco inicial a Carta Magna de 1988; num segundo momento, abordamos o processo de implementação do modelo de gestão do Território Etnoeducacional no estado da Bahia. Em seguida, apontamos o resultado material da política, através do diagnóstico do Projeto Observatório. No tópico quatro, correlacionamos esse resultado com os problemas de implementação. Por fim, desenvolvemos algumas considerações sobre o atual estado da política educacional e seu caráter de política de reconhecimento.

2 O autor foi bolsista de iniciação científica e Jéssica T. C. e Silva participou como pesquisadora voluntária no Projeto. 


\section{BREVE hISTÓRICO DA POLÍtICA EDUCACIONAL PARA POVOS INDÍGENAS}

A história republicana do Brasil não tem muito do que se orgulhar das relações entre povos indígenas e o Estado. Desde a fundação do Serviço de Proteção aos Índios e Localização de Trabalhadores Nacionais, no ano de 1910 até a Constituição de 1988, as ações governamentais em aldeias indígenas foram regidas pelo paradigma jurídico e político da integração à sociedade nacional e pela ideologia da assimilação cultural. Dessa forma, a política educacional visava a inserção dos diferentes povos indígenas na economia de mercado, integrando-os à sociedade envolvente por meio do trabalho, sem respeitar seus processos próprios de ensino e socialização de conhecimentos, suas línguas, identidades e projetos comunitários.

A Constituição de 1988 põe fim ao paradigma integracionista ao reconhecer o direito dos índios de serem eles mesmos. O texto constitucional dedica, no Título VIII - Da Ordem Social, um capítulo exclusivo sobre os direitos dos índios, no qual reconhece a sua organização social, costumes, línguas e tradições, além dos direitos originários sobre o território que ocupam. Destaca-se também, no Capítulo III - Da Educação, o direito ao uso da língua materna e dos processos próprios de aprendizagem, cabendo à União garanti-los (Silva 2008).

A partir da prerrogativa jurídica postulada pela Carta Magna, leis e regulamentos modificaram as ações governamentais na educação formal para indígenas, ensejando mudanças em termos de princípios e nas instituições que formulam e executam a política. Dentre as principais regulamentações podemos citar:

O Decreto Presidencial no 26 e a Portaria Interministerial MJ/MEC n. 559, ambos de 1991, transferem a responsabilidade pela educação indígena da Fundação Nacional do Índio (FUNAI) para o Ministério da Educação (MEC) e para os estados e municípios; Lei no 9.394/96, que estabelece as Diretrizes e Bases da Educação Nacional (LDB); o Parecer 14 e a Resolução no 3 do Conselho Nacional de Educação, ambos de 1999, estabelecem as Diretrizes Nacionais da Educação Escolar Indígena; a Lei 10.172, de janeiro de 2001, que estabelece o Plano Nacional de Educação, com prazo de 10 anos para sua execução; e o Decreto 5.051/04, que ratifica a Convenção no 169 da Organização Internacional do Trabalho33. O MEC também publicou documentos de orientação para as escolas indígenas, como o Referencial Curricular Nacional para as Escolas Indígenas (Brasil 1998) e os Referenciais para a Formação de Professores Indígenas (Brasil 2002).

Essa legislação regulamenta uma política laica, diferenciada, que respeita os costumes, tradições, línguas e processos próprios de aprendizagem e as organizações sociais dos povos indígenas. Também destaca o caráter intercultural como princípio para as escolas indígenas, ao versar sobre o acesso ao conhecimento e domínio dos códigos da sociedade nacional, mas enquanto etnias culturalmente diferenciadas. As mudanças jurídicas e políticas ensejadas incluem a consulta às populações indígenas sobre ações governamentais que incidam sobre seus territórios, a universalização do Ensino Básico, bem como o respeito à diversidade sociocultural, através do reconhecimento da 'categoria escola indígena', com sua organização jurídica própria, garantia de ensino bilíngue, funcionamento de escolas no interior de aldeias indígenas - evitando, assim, afastar as crianças do convívio familiar e comunitário -, construção de escolas nos padrões arquitetônicos de cada grupo, calendário escolar, currículo e regimentos próprios, formação de

3 Essa legislação pode ser encontrada na publicação organizada por Luiz Fernando Villares Silva (2008). 
professores indígenas, utilização de material didático específico e incorporação dos conceitos de educação específica, diferenciada e intercultural.

Em relação aos recursos financeiros, a legislação regulamenta que esses sejam oriundos de impostos da União, dos estados e dos municípios, do Fundo Nacional de Manutenção e Desenvolvimento da Educação Básica e de Valorização dos Profissionais da Educação (FUNDEB), cujos recursos são repassados de acordo com um valor mínimo estabelecido para a categoria "Educação Indígena e Quilombola" e por coeficientes de distribuição, calculados pelo número de matrículas dos municípios e estados. Além disso, pelo fato das escolas pertencerem aos sistemas municipais e estaduais, essas recebem recursos dos programas do Fundo Nacional de Desenvolvimento da Educação (FNDE), como o Programa Dinheiro Direto na Escola (PDDE), Programa Nacional de Alimentação Escolar Indígena (PNAEI) e Programa Nacional do Livro Didático (PNLD), entre outros.

Em termos institucionais, a política educacional, até então de exclusiva responsabilidade do órgão indigenista, a Fundação Nacional do Índio, passa a ser coordenada pelo Ministério da Educação, contando com órgãos específicos para tratar da questão em sua estrutura administrativa $^{4}$, e executada pelas secretarias municipais e estaduais de educação, através de um regime de colaboração entre as três esferas de governo.

No caso específico do estado da Bahia, há uma legislação que regulamenta as escolas indígenas, baseada nas leis federais descritas acima. No ano de 2007, ocorrem mudanças institucionais na Secretaria da Educação do Estado da Bahia (SEC-Ba), como a desvinculação prática da Coordenação do Campo da Coordenação Indígena, sendo essa última coordenada por uma indígena do povo Tuxá. Além disso, criam-se Coordenações Indígenas em 14 Diretorias Regionais de Educação, também ocupadas por representantes indígenas. Dessa forma, em tese, o aparato burocrático do Estado torna-se mais participativo e responsivo diante das demandas dos públicos-alvo.

\section{Processo de implementação do terRitório etnoeducacional}

Dando continuidade às regulamentações legais no âmbito da educação escolar indígena, no ano de 2009, o então Presidente Luis Inácio Lula da Silva assinou o Decreto No 6.861, que institui uma forma de gestão das políticas educacionais para os povos indígenas, através dos Territórios Etnoeducacionais (TEe). O Decreto institui um mecanismo jurídico-administrativo inovador, estabelecendo que "[...] cada Território Etnoeducacional compreenderá, independentemente da divisão político-administrativa do País, as terras indígenas, mesmo que descontínuas, ocupadas por povos indígenas" (Brasil 2009a: 25).

A administração da educação escolar indígena continua a ser coordenada pelo Ministério da Educação, sendo executada pelos estados e municípios presentes no Território estabelecido. O MEC define os Territórios, sendo ouvidas as comunidades indígenas, os entes federativos envolvidos, a Fundação Nacional do Índio, a Comissão Nacional de Educação Escolar

\footnotetext{
4 No ano de 2004 é criada, na estrutura administrativa do MEC, a Secretaria de Educação Continuada,
} Alfabetização e Diversidade, contando com uma Coordenação Geral de Educação Escolar Indígena. 
Indígena, os Conselhos Estaduais de Educação Escolar Indígena e a Comissão Nacional de Política Indigenista.

No decreto considera-se, em princípio, a organização territorial indígena, pois permite estabelecer um Território que compreenda as terras de um povo ou de vários povos, mesmo que esses estejam presentes em diversos municípios ou estados. Sabemos que os povos indígenas muitas vezes não coincidem sua ocupação territorial com as unidades da divisão geopolítica do Estado brasileiro. Por exemplo, povos como o Pataxó ocupam diferentes estados. Já outros, como o Guarani, estão presentes em mais de um país. Essas diferentes disposições de ocupação territorial, combinadas ao federalismo brasileiro, têm levado a situações como a relatada por Gersem dos Santos Luciano:

[...] em que um povo que fala a mesma língua, mas, em um estado este povo é atendido com uma escola bilíngue e ensino médio, material didático próprio e com formação de professores em nível superior, enquanto que, em outro estado, este mesmo povo não dispõe de nada disso e sua luta ainda se concentra no atendimento das primeiras séries do ensino fundamental. (2011:09)

Em tese, estaríamos diante de uma resposta ao problema da fragmentação do serviço educacional oferecido às populações indígenas, pois abre-se a possibilidade de se fortalecer o regime de colaboração entre o Governo Federal e as unidades subnacionais, por meio de uma Comissão que irá gerir o Território. $\mathrm{O}$ decreto expressa o vínculo entre os entes federativos, mas também promove a ampliação do número de atores que participam das decisões referentes à política educacional no interior do Território, pois organizações não governamentais e os povos indígenas têm suas representações garantidas nessa Comissão Gestora ${ }^{5}$.

Uma das funções dessa Comissão é criar um Plano de Ação, que deve ser composto por um diagnóstico da situação educacional do Território e por um planejamento de ações para atender as demandas. O processo de construção do plano de ação do Território Etnoeducacional Yby Yara foi acompanhado por nós e serviu de base para a análise apresentada neste texto.

\section{Construção do Tee Yby Yara}

O processo de implementação do TEe no estado da Bahia foi iniciado ao longo de três reuniões realizadas no ano de 2010. Num primeiro momento, com a participação de representantes do MEC, da FUNAI e de povos indígenas da região nordeste, foi deliberado que o Território Etnoeducacional, de nome Yby Yara ${ }^{6}$, seria composto pelos 14 povos indígenas no estado da Bahia. Numa segunda reunião, foi composta a Comissão Gestora. As principais funções dessa Comissão dizem respeito ao plano de ação do TEe, sendo essa responsável pela elaboração, pelo acompanhamento da execução do plano e por sua revisão. Um dos pontos importantes desse plano de ação é o diagnóstico da situação do TEe, que foi confeccionado durante um encontro

5 De acordo do com o Decreto 6.861/09, a Comissão deve ser composta por representantes do MEC, FUNAI, um representante de cada povo indígena que habita o Território, entidades indigenistas, Secretários de Educação dos Estados, do Distrito Federal e Municípios presentes no Território estabelecido, e ainda aceitar a admissão de outros membros, como representantes do Ministério Público, das instituições de educação superior, das redes de formação profissional e tecnológica ou de outros órgãos ou entidades que desenvolvam ações voltadas para a educação escolar indígena.

6 Segundo definição dos indígenas do povo Tupinambá, o termo significa “donos da terra” em Tupi. 
amplo, envolvendo as representações da Comissão Gestora, como lideranças indígenas, professores e pesquisadores universitários, organizações não governamentais, FUNAI, MEC, secretarias municiais e secretaria estadual da educação.

Registre-se a ocorrência de uma reunião no ano de 2011, na qual foi estabelecido o regimento da Comissão Gestora e elencadas suas atribuições. Porém, desde então, o processo de implantação do Território Etnoeducacional está parado. A Comissão Gestora, promovida para catalisar o regime de colaboração entre os entes federativos e demais instituições que atuam na educação escolar indígena, não tem funcionado como previsto, pois a grande maioria das secretarias municipais não participa. Além disso, as reuniões dessa Comissão dependem de diversos atores, dificultando a eficiência do processo de implantação. Por exemplo, no ano de 2012, a morosidade no processo de repasse de verbas entre o MEC e a FUNAI resultou na realização de uma única reunião da Comissão, no mês de dezembro, às vésperas do natal, com o convite enviado para os participantes uma semana antes do evento. Assim, o Território Etnoeducacional, por enquanto, só existe em nossas intenções e papeis de pactuação, posto que as ações continuam sendo realizadas de forma isolada pelas instituições responsáveis pela política de educação.

Entretanto, é nesse contexto de fragmentação e descontinuidade dos serviços públicos educacionais que emerge um forte protagonismo político de indivíduos e organizações indígenas e de parceiros desses atores. Por exemplo, a proposta inicial dos Territórios Etnoeducacionais foi modificada durante o seu processo de implantação. Na I Conferência de Educação Escolar Indígena, no ano de 2009, o Governo Federal, por meio do MEC, propôs três Territórios para a região Nordeste. Desde a Conferência, as lideranças indígenas e indigenistas questionaram os critérios utilizados nas delimitações, ora solicitando novas configurações para os Territórios, ora reivindicando a construção de um sistema próprio para a educação escolar indígena. A negociação com o governo culminou, para o caso da Bahia, na construção de um só Território que abarcasse o estado, e três Territórios no restante do Nordeste.

Além disso, durante o encontro, no qual foi confeccionado o diagnóstico da Comissão Gestora, houve forte participação de professores indígenas, indigenistas, professores universitários e participantes de organizações não governamentais, que completaram muitas das informações sobre a realidade educacional no estado, pois os dados oficiais estavam defasados.

Gostaríamos de destacar que participei de todo o processo de construção desse Território, inclusive como representante indígena na Comissão Gestora. Pudemos observar e participar de um rico processo de protagonismos de sujeitos historicamente marginalizados no que tange à construção de políticas públicas, não obstante a descontinuidade de tal política. Não queremos com isso diminuir a problemática desse modelo de gestão, mas sim ressaltar a importância da participação indígena em processos democráticos de deliberação pública. Há uma forte potência nesse protagonismo, presente na constituição da cidadania por meio da participação na comunidade política brasileira e na construção de políticas mais efetivas quando construídas com informações mais precisas sobre os públicos aos quais se destinam. Assim, entendemos que a participação não é a parte problemática do processo aqui analisado, mas sim os desdobramentos da política, principalmente em relação à continuidade de sua execução. 


\section{Resultado material da Política de eduCAÇão escolar INDÍGENA}

O diagnóstico desenvolvido pelo Projeto Observatório da Educação Escolar Indígena, através de seus pesquisadores, colaboradores e bolsistas indígenas em suas comunidades, permite-nos traçar um panorama da situação do Território Yby Yara. Esse Projeto, que compõe a Comissão Gestora do referido Território, e está institucionalmente vinculado ao Programa Multidisciplinar de Estudos Étnicos e Africanos da Universidade Federal da Bahia, atua em cooperação com a Licenciatura Intercultural da Educação Escolar Indígena, da Universidade do Estado da Bahia (UNEB). Ele visa à inserção dos professores indígenas nos projetos de pesquisa em educação e produção conjunta de material didático, tendo, como um dos seus instrumentos, a base de dados do Instituto Nacional de Estudos e Pesquisas Educacionais Anísio Teixeira (INEP) ${ }^{7}$, direcionada para o campo específico da educação escolar indígena. Numa de suas metas, propõe a construção de uma cartografia da educação indígena na Bahia, tendo como base inicial as fontes de dados do INEP e a pesquisa desenvolvida por bolsistas para a elaboração de um diagnóstico do Território Etnoeducacional Yby Yara.

Os bolsistas do Observatório utilizam questionários e entrevistas semi-estruturadas, visando ao levantamento de dados quantitativos e qualitativos sobre a educação em suas respectivas aldeias. Esses instrumentos de pesquisa são baseados em categorias do INEP, como quantidade de professores e de alunos, e também em categorias elaboradas pelos bolsistas, através das entrevistas e depoimentos de pessoas das aldeias, como a quantidade de alunos indígenas que estudam externamente às áreas indígenas.

Assim, no ano de 2010 diagnosticamos 60 escolas indígenas, nas quais lecionam 420 professores e estudam 7.730 alunos. Dessas 60 escolas, 51 são municipais e apenas 09 estavam sob responsabilidade direta do sistema de ensino estadual ${ }^{8}$. Isso explica o fato de apenas 06 escolas oferecerem turmas de Ensino Médio, posto que esse ensino é prerrogativa das escolas estaduais, enquanto o restante só oferta turmas do Ensino Fundamental. Interessante notar que apenas três escolas não estavam localizadas em terras indígenas legalmente demarcadas.

Em relação ao material didático específico, elaborado por professores indígenas, 43 escolas utilizam-no, enquanto 17 somente utilizam os livros didáticos nacionais. Porém, verifica-se que o material didático específico é utilizado somente nas turmas iniciais do Ensino Fundamental, limitando a ideia de interculturalidade na prática de ensino e aprendizagem das turmas de Ensino Médio. Todas as escolas dispõem de fornecimento de merenda escolar, mas relata-se inadequação do cardápio oferecido na merenda e a descontinuidade na oferta desse serviço público.

Em termos de estrutura física, 42 funcionam em prédios escolares, 08 das quais contam com laboratório de informática e apenas 07 com salas de leitura ou biblioteca. Porém, 18 escolas não funcionam em prédios escolares e nenhuma possui laboratório de ciências. Além disso, o que os censos oficiais registram como prédio escolar mascara o grande déficit de implementação da rede física da educação escolar indígena, principalmente na rede municipal de ensino. Em

$7 \quad$ O Inep é uma autarquia federal vinculada ao Ministério da Educação, à qual cabe promover estudos, pesquisas e avaliações sobre o Sistema Educacional Brasileiro para subsidiar a formulação e implementação de políticas públicas para a área educacional.

8 Observamos, nos últimos anos, um processo de estadualização das escolas indígenas no estado da Bahia. No ano de 2013 encontramos 22 escolas estaduais. 
pesquisa de campo, constatei que muitas escolas funcionam em prédios improvisados, como casas de professores, igrejas, bares e casas de farinha. Além disso, há escolas que funcionam, de forma ainda mais improvisada, em armazéns de cacau, casas de barro, de lona e de palha.

Segundo dados do INEP de 2008 (Brasil 2009b), que contabilizava 6.969 alunos indígenas, a maioria dos estudantes - 4.993 - estava nas turmas iniciais do Ensino Fundamental, 995 em turmas de Educação Infantil, enquanto apenas 225 matriculados no Ensino Médio, número menor do que o de matrículas nas Turmas de Educação para Jovens e Adultos, que contavam com 726 alunos. A maioria desses estudantes estudava em turmas multisseriadas -1.205 , existindo somente 14 turmas unificadas. Em depoimentos, os professores indígenas apresentam como óbice para o processo de aprendizado do aluno o fato das turmas serem multisseriadas. Todos os alunos, independente da turma, assistem às aulas no mesmo horário e na mesma sala. A turma multisseriada é um problema enfrentado por indígenas em todo o estado. Nelas, os alunos, em diferentes estágios de formação, têm o aprendizado prejudicado, por não disporem de um atendimento mais especializado, de acordo com os conteúdos demandados pelo grau de formação de cada um.

Em relação aos professores, registra-se que já foram oferecidos dois cursos de Formação de Professores no Nível Médio, o chamado Magistério Indígena, que formaram cerca de 197 professores. Além disso, vale notar que nunca ocorreu um concurso específico para professores indígenas atuarem em sala de aula. Apesar de não termos o número exato, cerca de $90 \%$ dos 420 professores trabalham por regime de contrato, seja pelo município, seja pelo estado. A maior parte dos professores das escolas estaduais trabalha sob o Regime Especial de Direito Administrativo (REDA), cujo tempo máximo de duração do contrato é de 04 anos. Há professores e demais servidores, como merendeiras, faxineiros, zeladores e vigias, que trabalham pelo regime de Prestação de Serviço Temporário (PST). Nesse tipo de contrato, utilizado para pagamento de estagiários, negam-se os direitos trabalhistas aos servidores, como férias, décimo terceiro salário, seguro-desemprego, além de não terem garantias sobre a continuidade dos

contratos. Nos municípios, os contratos são anuais, expondo os professores e servidores a uma situação de vulnerabilidade trabalhista, posto que esses estão em situação semelhante aos que são contratados via PST.

\section{DÉFICITS DE IMPLEMENTAÇÃo DA POLÍtICA DE TERRITÓRIOS ETNOEDUCACIONAIS}

Diante desse quadro, verifica-se uma inadequação entre a legislação que regulamenta a política de educação para povos indígenas e o seu resultado material. A legislação, os planos e programas evidenciados no tópico I apresentam-nos uma realidade muito distante da encontrada nas aldeias indígenas no Território Etnoeducacional Yby Yara. De forma sumária, tentaremos abordar, neste tópico, indícios dos condicionantes negativos do desenho da política sobre a sua implementação, tendo essa como variável explicativa da inadequação entre a legislação em vigor e o resultado final da política pública. 
O pressuposto teórico do ciclo da política apresenta, em geral, quatro fases de uma política pública: formação da agenda do governo, elaboração, implementação e avaliação. Desde a década de 1960, Charles Lindblom afasta a ciência política das perspectivas do direito e da administração pública, que consideravam a implementação como uma fase automática da política, na qual se cumpriam os cursos de ação elaborados nos planos, leis, metas e programas de governos. Sua análise demonstra como a implementação é uma fase autônoma da vida de uma política pública, ensejando decisões, além de modificar os cursos de ação inicialmente planejados, reformulando a própria política (Lindblom 1981). Concebemos esse modelo cíclico como um construto metodológico para entender relações que no concreto real são mais dinâmicas e imbricadas. Porém, tal construto, oriundo de uma análise sistêmica dos processos políticos, é útil para compreendermos os déficits anunciados anteriormente.

Assim, com base nesse modelo analítico, entendemos que a inadequação entre a legislação e o resultado final da política pode ser explicada pelos processos de implementação. Neste artigo desenvolvemos a ideia de que o desenho da política, em especial o regime de colaboração entre os entes do sistema federativo brasileiro, condiciona negativamente o processo de implementação. Vejamos.

Segundo exposto no tópico I, a política de educação escolar indígena é coordenada pelo MEC e executada pelas unidades subnacionais. Porém, a legislação que trata do assunto não define claramente as responsabilidades dos entes federativos. O Conselho Nacional de Educação constatou tal vácuo institucional e emitiu o Parecer 14 e a Resolução no 03, ambas no ano de 1999, considerando que, dadas as peculiaridades da educação escolar indígena, os sistemas de ensino estaduais devem se responsabilizar por ela, apresentando-se como competência dos municípios somente quando esses disporem de recursos financeiros e técnicos para tanto, atuando em colaboração com o sistema estadual e sob a anuência das comunidades indígenas.

Porém, quando da implementação da política de educação pós-Constituição na Bahia, os policy makers ${ }^{9}$ adotaram como referência os postulados da Lei de Diretrizes e Bases, de 1996, que apontam como prerrogativa do sistema estadual de educação o atendimento às escolas que ofertam turmas de Ensino Médio, assim como coloca sob a responsabilidade dos sistemas municipais as escolas que ofertam Ensino Fundamental. Diante disso, observa-se que a maioria das escolas indígenas, 51 ao todo, é vinculada aos municípios, e apenas 09 são estaduais. As burocracias municipais, pouco preparadas técnica e financeiramente para tratar da educação escolar indígena enquanto uma política intercultural, absorveram a burocracia federal, responsável pela elaboração da política em termos de resoluções, pareceres, planos e programas.

As secretarias municipais não oferecem à maioria das escolas indígenas apoio para a formulação de projetos políticos pedagógicos próprios, merenda escolar com cardápio diferenciado ou construção de escolas de acordo com as características arquitetônicas requeridas pelas aldeias.

Além do despreparo técnico, as receitas de impostos dos municípios e os recursos financeiros captados pelo FUNDEB e FNDE não têm surtido efeito para dirimir os déficits, como o de construção de escolas. Tais recursos são baseados em coeficientes de distribuição, que em geral

9 Políticos e burocratas que elaboram uma política pública. 
levam em consideração a relação de matrículas do sistema de ensino. Mesmo com os valores mínimos de aplicação, como as escolas indígenas têm baixa densidade na relação entre professor/ aluno/escola, esses recursos se tornam insuficientes. Além disso, enfrentam-se os problemas de gestão presentes nas secretarias municipais e estadual. Em alguns casos, mesmo com o recurso descentralizado pelo FNDE, atrasos nos processos de prestação de contas acarretam a descontinuidade dos serviços de merenda e transporte escolar.

Por fim, observamos a problemática da representação social e imagética sobre o índio. Em muitos municípios baianos os povos indígenas são vistos como privilegiados. Diante de um quadro de desigualdade social aguda, como o da sociedade brasileira, garantir direitos específicos para um determinado grupo ressoa como privilégio e não como direito. Não bastasse a imagem historicamente distorcida sobre os povos indígenas, em muitos casos esses estão em conflito aberto com o Poder Público Municipal, devido às disputas fundiárias. Assim, encontramos relatos de gestores públicos que consideram desnecessária uma escola somente para indígenas ou não entendem o porquê da existência de tal política, além dos casos extremos nos quais alunos indígenas, que estudam em escolas não indígenas das cidades em seu entorno, são proibidos de acessar a escola, devido a ameaças de apedrejamento.

Revelador desse quadro é o dado de que dos 19 municípios com escolas indígenas, somente 04 contam com coordenações indígenas em sua estrutura administrativa. Muitos municípios inserem as escolas indígenas em Coordenações do Campo, não oferecem apoio à construção de um projeto político pedagógico próprio, ao uso de material didático específico e à contratação de professores indígenas em regimes específicos de contrato, ou mesmo por concursos diferenciados.

Tentando contornar essa dificuldade, o Decreto que instaura os Territórios Etnoeducacionais regulamenta que a educação escolar indígena seja gerida por uma Comissão Gestora, da qual devem participar, obrigatoriamente, secretarias municipais, estaduais e representantes indígenas. Porém, no processo de implementação do Território, ao acompanharmos todas as reuniões, verificamos que apenas 08 secretarias municipais participaram. A explicação de tal liberdade de ação encontra-se no desenho da política. A regulamentação federal, devido à diversidade do público-alvo, é muito aberta e genérica, expondo princípios e prerrogativas, mas sem elementos de sanção para com as instituições públicas que não cumpram com seus deveres. Encontramos na análise documental termos como 'estimular', 'participar', 'garantir', e poucos termos como 'sancionar' e 'é dever'. As regulamentações deixam em aberto a responsabilidade sobre a educação escolar indígena, permitindo situações de políticas pouco institucionalizadas, como no caso da Bahia. Infelizmente, de forma metafórica, há de se concordar com o velho Hobbes: “[...] os pactos, não passando de palavras e vento, não têm qualquer força para obrigar, dominar, constranger ou proteger ninguém, a não ser os que derivam da espada pública.” (1994: 151).

\section{Condiderações finais}

Apesar da problemática apresentada, não se pode negar o crescimento vertiginoso das ações governamentais para a educação escolar indígena. Vinte e cinco anos após a Promulgação da Constituição de 1988, construímos uma legislação sólida que abarca diferentes dimensões dos processos educacionais de ensino e aprendizagem nas aldeias indígenas. Da estrutura física 
à formação de professores, reconhece-se o caráter intercultural da educação escolar indígena. Além disso, uma série de mudanças institucionais criaram estruturas burocráticas para atender à elaboração e execução da política.

Porém, o desenho da política deve ser redimensionado, tendo em vista a forma como o sistema político brasileiro converte as demandas da sociedade civil em ações de governo. O regime de colaboração entre os entes federativos, ao contrário do que previram nossos legisladores, tem sido pouco eficiente na execução de uma política efetivamente intercultural. Talvez seja o momento dos nossos policy makers, em diálogo com as populações indígenas, repensarem o desenho da política, optando por uma medida conservadora que envolva a centralização administrativa na esfera federal de governo.

A centralização pode representar ganhos em termos de eficácia e eficiência da política, ao diminuir o número de pontos de vetos das decisões, concentrar captação e execução de recursos numa única unidade administrativa federal, que, inclusive, pelo histórico da política e pela formulação de planos e programas, mostre-se mais sensível à especificidade indígena do que as burocracias municipais.

Como pudemos constatar no trabalho de campo nas escolas e nos depoimentos de pesquisadores indígenas, a escola tem se tornado um espaço central para a reafirmação étnica, recuperando a autoestima de indivíduos e grupos que se identificam enquanto indígenas. Os professores indígenas dentro das salas de aula, alunos sendo atendidos em suas respectivas comunidades, a elaboração de alguns materiais didáticos específicos, aulas que abordam aspectos simbólicos e culturais dos povos indígenas, como as aulas de direito indígena, sobre grafismo, pintura, história indígena, são elementos positivos dentro dessa nova escola.

A construção da identidade individual e coletiva perpassa o exercício da alteridade, isto é, constrói-se uma identidade a partir da interação com os 'outros-importantes', sendo esses outros constituídos pelos grupos primários nos quais os indivíduos são formados e/ou pela sociedade como um todo (Taylor 1999). Assim, as políticas de reconhecimento permitem modificações na formação de uma auto-imagem depreciativa de indivíduos e grupos, e a sobrevivência cultural desses grupos, no sentido de garantir às gerações futuras a oportunidade de escolherem a permanência de determinados padrões próprios de sociabilidade, como a língua a ser falada ou o tipo de educação a ser transmitida (Taylor 1999; Appiah 1999).

Minorias étnicas, como os mais de 200 povos indígenas presentes no território brasileiro, têm na política de educação, entendida por nós como uma política de reconhecimento, um potencial exercício de desenvolvimento de seu protagonismo político. Compreendemos que a educação formal pode contribuir para outras formas de interação entre as aldeias e a chamada sociedade envolvente, por meio da intermediação de saberes que a escola pode propiciar.

Assim, evidenciar a implementação insatisfatória da política de educação escolar indígena, em nossa concepção, é contribuir para esse novo papel da escola dentro das aldeias, que valorize a realidade local nos processos de ensino e aprendizagem, consolidando a liberdade de escolha para indivíduos e grupos sobre o presente e o futuro das coletividades às quais pertencem. 


\section{REFERÊNCIAS}

Appiah, K.A. 1994. "Identidade, autenticidade e sobrevivência." In Multiculturalismo, organizado por Amy Gutmann. Lisboa, LIS: Instituto Piaget.

Brasil. 1998. Referencial curricular nacional para as escolas indígenas. Brasília, DF: MEC/SEF. 2002. Referenciais para a formação de professores indigenas. Brasília, DF: MEC/SEF. Decreto no 6.861. Dispõe sobre a Educação Escolar Indígena, define sua organização em Territórios Etnoeducacionais, e dá outras providências. Diário Oficial [da] República Federativa do Brasil, Poder Executivo, Brasília, DF, 28 maio. 2009a. Seção 1, p. 23-25. Disponível em: < http:/www.in.gov.br/visualiza/index.jsp?jornal=1\&pagina=23\&da $\mathrm{ta}=28 / 05 / 2009>$. Acesso em: 29 dez. 2009a.

.2009b. Um olhar sobre a educação indígena com base no censo escolar de 2008. Brasília, DF: Inep.

Grupioni, Luís Donisete Benzi (Org.).2005. As leis e a educação escolar indígena: programa parâmetros em ação de educação escolar indígena. 2. ed. Brasília, DF: MEC/SECAD.

Hobbes, Thomas. 1994. O Leviatã. São Paulo, SP: Editora Nova Cultura.

Lindblom, Charles Edward. 1981. O processo de decisão politica. Tradução Sérgio Bath. Brasília, DF: Editora Universidade de Brasília.

Luciano, Gersem dos Santos. 2011. Territórios Etnoeducaionais: um novo paradigma na politica educacional brasileira. Brasília, DF: MEC. Disponível em: <http://www.cinep.org.br/uploads/e42d706bbd109ef3e5c5b8b41e310eeab53c3dd5.pdf>Acesso em: 27 fev. 2011.

Silva, Luiz Fernando Villares (Org.). 2008. Coletânea da legislação indigenista brasileira. Brasília, DF: CGDTI/FUNAI.

Taylor, Charles. 1994. "A política de reconhecimento". In Multiculturalismo, organizado por Amy Gutmann. Lisboa, LIS: Instituto Piaget.

\section{THE TERRITORIALIZED MANAGEMENT MODEL OF THE INDIGENOUS EDUCATION POLICY IN THE STATE OF BAHIA, BRAZIL}

In this article, based on research conducted by the "Projeto Observatório - Núcleo Yby Yara", we discuss the institutional limits of the management model of "Territórios Etnoeducacionais" and the implementation of an intercultural policy of indigenous education. The project in question proposes a set of actions aimed to foster indigenous protagonism through the training of indigenous professors and researchers, production of intercultural knowledge and political and academic articulation, stimulating and subsidizing educational and research initiatives in the newly created "Territorios Etnoeducacionais". Within this context, the article analyzes some of the theoretical and methodological issues related to the implementation of public policies for indigenous peoples, aiming to contribute towards the evaluation of such policies, still of little concern to governmental agencies and scientific research alike.

Keywords: public policies; indigenous education; Territórios Etnoeducacionais. 